\title{
Biological Attributions for Political Ideology decrease Political Prejudice and Intolerance
}

\author{
Melissa N. Baker \\ Department of Political Science \\ University of California, Merced \\ mbaker25@ucmerced.edu \\ Ingrid J. Haas \\ Department of Political Science \\ Center for Brain, Biology, and Behavior \\ University of Nebraska-Lincoln
}

Manuscript in preparation (October 2020). Please do not cite without permission.

\begin{abstract}
Does attributing the roots of political ideology to biology influence political tolerance and how people feel about political outgroups? In this paper, we examine the effects of attributing political ideology to biology, as opposed to personal choices that are more malleable, on political prejudice, intolerance, and perceptions of political polarization. Using an experimental paradigm, we encouraged respondents to think about political ideology as either rooted in biology or as a personal choice that is not fixed. Results from two experiments suggest that encouraging individuals to attribute political ideology to biology leads to decreased political prejudice, decreased political intolerance, and a perception of less political polarization.
\end{abstract}

Keywords: attribution, tolerance, prejudice, polarization, biopolitics 
A growing body of literature has explored biological differences between liberals and conservatives, whether it be in brain structure, brain function, genetic phenotypes, hormones, or other cognitive and personality differences. For example, research on the relationship between genetics and politics has found that political attitudes are more influenced by genes than parental socialization (Alford, Funk, and Hibbing 2005) and variation in voter turnout is partially explained by genes (Fowler, Baker, and Dawes 2008; for a more in-depth summary of the findings see Hatemi and McDermott 2011; Hibbing, Smith, and Alford 2013). Work has yet to examine whether being exposed to this information about the biological and psychological foundations of political ideology changes how people perceive political groups. Does attributing the roots of political ideology to biology influence prejudicial attitudes and intolerance?

Causal attribution is a tool individuals use to make sense of their world and in particular, understand the causes of human beliefs and behavior. Explaining the source of ideological beliefs helps people explain why they and others hold their respective political ideologies. In this paper, we focus on internal causal attributions, or the cause of political ideology being an internal characteristic or behavior (e.g., political ideology is shaped by genetics), as opposed to external causal attributions such as the environment (e.g., political ideology is shaped by socialization). Previous studies on causal attribution have focused on issues such as sexual orientation and have found that when people attribute sexual orientation to biological foundations (i.e., genetics), they tend to have more positive views about homosexuals, express more tolerance of homosexuality, and are more likely to support individual rights for homosexuals, such as same-sex marriage or same-sex couples adopting children (Haider-Markel and Joslyn 2008; Hegarty 2002). Similar studies have also found that the causal relationship may go in both directions (i.e., support for rights leads to biological attributions and biological 
attributions leads to support for rights) or be moderated by political ideology (i.e., biological attributions are related to an increase in support for homosexual rights for liberals, but not conservatives; Garretson and Suhay 2016). Other studies have found that the tendency to make biological attributions for ideology is related to greater intolerance (Suhay, Brandt, and Proulx 2017). Due to the correlational nature of these studies it is unclear whether biological attributions lead to more positive attitudes and higher tolerance, more positive attitudes and higher tolerance lead to biological attributions, other third variables influence the relationship between attributions, attitudes, and tolerance, or if the causal arrow goes in both directions. In this paper, we seek to examine the causal nature of the relationship between attributions, prejudice, and tolerance in relation to politics using an experimental approach. It has been suggested that this mechanism should transfer to political ideology such that biological attributions should decrease negative attitudes and increase tolerance (Hibbing, Smith, and Alford 2013). If people see biology as the foundation of political ideology, they should express less prejudice and less intolerance toward their political outgroup because people are less likely to blame individuals for traits they are born with and cannot control.

Alternatively, under the framework of Social Identity Theory (Tajfel 1970; Tajfel et al. 1971), biological attributions may lead to more prejudice and intolerance. Social Identity Theory suggests that essentialist thinking, or the belief that social categories have an underlying nature or natural foundation (Keller 2005), tends to be related to an exaggeration of group differences. This exaggeration is commonly found in work in psychology on race and prejudice (Rothbart and Taylor 1992), where those who believe people of different races are biologically very different tend to express more racial prejudice. In a political context, attributing political ideology to a biological or genetic foundation may lead to a contrast effect whereby liberals and 
conservatives seem like two completely separate groups, rather than two groups on a continuum that may share overlapping traits. This may increase perceptions of political polarization since the two groups seem more distant. While essentializing could have negative consequences for prejudice and tolerance, essentializing magnifies boundary divisions and these divisions help people distinguish between political groups, which aids in the ability to make distinctions between them (Nicholson et al 2018). Collectively, past research suggests biological attributions could lead to an increase or decrease in prejudice and intolerance. More work is needed to understand the direction of this relationship.

In the present work, we conducted two experiments in order to examine the causal effect of biological attributions for ideology on prejudice, intolerance, and political polarization. In Experiment 1, we found that attributing political ideology to biology led to decreased political prejudice. Results of Experiment 2 showed that attributing political ideology to biology led to an increase in tolerance toward ideological outgroups and reduced perceptions of political polarization.

Taken as a whole, this work suggests that how people explain the causes of political ideology can have an effect on attitudes toward political outgroups. When individuals were given information suggesting political ideology has biological roots they expressed less prejudice and intolerance tolerance toward ideological outgroups. These results could have implications for intergroup relations since, much like the shift we have seen in public opinion about homosexuality, as people learn about the biological foundations of political ideology their prejudice may decrease. 


\section{Attributions, Prejudice, and Intolerance}

Previous research concerning attitudes as a function of attributions has largely focused on sexual orientation, framed by the political debate of whether homosexuality is something that is determined at birth or a lifestyle choice. Survey data has shown that individuals who believe sexual orientation is something you are born with tend to support same-sex marriage at a higher rate than individuals who believe sexual orientation is a lifestyle choice (Haider-Markel and Joslyn 2008). This sentiment is also expressed in general attitudes about sexual orientation; more positive views are expressed about homosexuals if individuals believe sexual orientation is inherent (Hegarty 2001). The present research extends these relationships to politics, such that thinking about political ideology as an inherent biological trait should affect affinity towards and willingness to extend civil liberties to political outgroups.

When an individual is evaluating a political outgroup, they may hold more negative attitudes about the group in question than a group in which they identify since, according to Social Identity Theory (Tajfel 1970; Tajfel et al. 1971), group membership affects social perceptions and judgements. The same is true regarding attribution--an individual who attributes political ideology to biology may have less prejudice against their ideological outgroup (liberal or conservative), much like heterosexuals have more favorable attitudes towards homosexuals when attributing sexual orientation to biology ${ }^{1}$. These attitude differences stem from an inclination that people who are born with a trait cannot help it therefore should not be judged that comes with biological attribution. If biology somehow predetermines traits such as political

\footnotetext{
${ }^{1}$ While we acknowledge research on and historical events surrounding genetic essentialism and race and/or ethnicity had discriminatory consequences, we expect political ideology to follow a similar trend to sexual orientation. Not only is there not a relationship between biological attributions and negative racial attitudes (Schneider, Smith, and Hibbing 2018), the level of biological influence on sexual orientation and political ideology has typically been underestimated whereas the level of biological influence on race/ethnicity has typically been overestimated. We expect the normative dialogue about sexual orientation and political ideology to be more similar than political ideology and race/ethnicity.
} 
ideology, individuals should be more sympathetic, both in terms of attitudes and tolerance, to the ideological outgroup. Recent work suggests this is the case, finding that genetic attributions for various mostly apolitical traits were related to an increase in tolerance for groups that are sometimes negatively stereotyped, such as homosexuals and drug addicts (Schneider, Smith, and Hibbing 2018). This sympathy manifests from a belief the outgroup cannot do anything about this biological predisposition and has little to no control over their ideological views.

\section{Attributions and Perceptions of Polarization}

The impact of attribution on perceptions of political polarization is perhaps less clear from the existing literature. Political orientations are a highly entitatively perceived category (Haslam, et al. 2000), meaning people think of political orientation as a group-level phenomenon, abstract from the individual category members. More specifically, this research shows that people think of political orientations as highly cohesive groups. Additionally, essentialism tends to make people think about categorical boundaries as rigid instead of flexible (Roberts, Ho, Rhodes, and Gelman 2017). This contributes to the perception of dichotomous categorical representations (Gelman 2003); people see two comparable groups, such as racial groups, as having very little in common and sometimes exaggerate the differences between groups (Rothbart and Taylor 1992). This has been shown in research on views of gender-holding more essentialist views on gender is associated with more favorable views of gender stereotypes (Coleman and Hong 2008).

Alternatively, the cognitive representation of ideology as a label with rigid boundaries could lead to clear differences in ideological groups but these may not be represented by a clear distance in ideological space. Instead, as previously outlined in regards to prejudice and intolerance, biological attributions for political ideology may just make people more sympathetic 
to outgroups and sympathize enough to be less aware of differences (or at least see these differences as less consequential). In this case, biological attributions would decrease perceptions of polarization, perhaps partially as a result of decreased prejudice and increased tolerance associated with this increased sympathy due to biological attributions.

\section{Overview of Present Work}

We conducted two experiments to test the effects of biological attributions on prejudice, intolerance, and perceptions of polarization. In both studies, we manipulated causal attributions for political ideology and then measured attitudes about political groups and polarization. We expected that (H1) attributing political ideology to biology would lead to reduced political prejudice. Biological attributions should create a mental representation where people assume that individuals cannot help or change what their political ideology is since it has a biological foundation. Relatedly, this same mental representation should lead people to be more tolerant of their political outgroups since it implies ideology cannot be chosen or changed. We expected that (H2) attributing political ideology to biology would lead to reduced intolerance directed toward ideological outgroups. Finally, attributing political ideology to biology should create distinct, rigid, categorizations of ideological groups. Having a mental representation of ideology as a rigid categorization means that Democrats are distinctively liberal and Republicans are distinctively conservative, and there is no room for people to deviate or occupy the gray (purple) area between the two. This could have implications for perceptions of polarization, but previous research has not clearly addressed what distinct categorizations may mean for perceived distance between Democrats and Republicans. It could be the case that essentializing creates distinct groups and those distinct categorizations produce a contrast effect and increase the perceived distance between groups, increasing perceived polarization. Alternatively, because we predict here that 
essentializing will decrease prejudice and intolerance, people may be less motivated to view the groups as highly distinct, which would decrease perceived polarization. Therefore, we expected that (H3) attributing political ideology to biology would influence perceptions of polarization, but we were agnostic as to the direction of this change.

\section{Experiment 1}

Experiment 1 was designed to test the first hypothesis, that attributing political ideology to biology would lead to more positive attitudes about ideological outgroups.

\section{Research Design}

We used a 3x2 (attribution: biology, choice, control x target ideology: liberal, conservative) between-groups experimental design to test hypothesis one. In this experiment, respondents were randomly assigned to read one vignette that encouraged them to think about political ideology as being rooted in either biology or personal choice (or a control condition). The vignette served as an attribution manipulation, encouraging respondents to think about political ideology as either a trait rooted in biology/genetics or as a malleable personal choice. Each vignette varied on both attribution type (biology, choice, control) and target ideology (liberal, conservative; see Appendix for full text). For analysis, we recoded target ideology as a function of participant ideology, such that this variable was coded in terms of whether participants read about an ingroup or outgroup member. After reading the vignette, respondents answered a manipulation check question that asked whether biology/genetics or personal choice is more influential in determining one's political ideology. Respondents then indicated how much they liked liberals and conservatives on a 7-point Likert scale, ranging from strongly dislike to strongly like, which was used as the primary dependent variable 2 .

\footnotetext{
${ }^{2}$ Respondents also answered questions about their political knowledge, political interest, and basic demographics.
} 
Respondents were a sample from Amazon's Mechanical Turk $(\mathrm{N}=202) .17$ participants were excluded because of missing data resulting from exiting the experiment before the manipulation or not answering dependent variable questions, leaving 185 cases for analysis. While some concerns have been raised about the use of Amazon's Mechanical Turk (AMT), we felt comfortable in using the platform for this experiment. Experiments run on AMT have been shown to replicate within the general population (Coppock 2018) and AMT users tend to have similar psychological dispositions to the general population (Clifford, Jewell, and Waggoner 2015). Participation in the experiment was restricted to residents of the United States and all participants were compensated \$1 USD for participation. $64 \%$ of the respondents were male, $66 \%$ identified as liberal and $34 \%$ identified as conservative, and the mean age was 32.8 ( $S D=$ 10.26). There was no difference in ideological extremity ${ }^{3}$ between liberals $(M=1.778, S D=$ $0.744)$ and conservatives $(M=1.786, S D=0.798 ; t(112)=-0.25, \mathrm{p}=0.947)$ in the sample.

\section{Manipulation Check}

In the manipulation check, respondents indicated whether they thought biology or personal choices were more influential in determining political ideology. In Experiment 1, approximately $8 \%$ of respondents in both the control and the choice conditions indicated that biology was the main influence in shaping political ideology, whereas approximately $50 \%$ of respondents in the biology condition indicated that biology was the main influence shaping political ideology. The difference between the biology and choice conditions was significant, $\left(X^{2}\right.$ $(1, N=193)=36.111, \mathrm{p}<0.001)$. This difference suggests that the manipulation worked as intended--respondents who were encouraged to think about political ideology as being rooted in

\footnotetext{
${ }^{3}$ Ideological extremity was computed using a 6-point ideology Likert scale. Extremity was scored as 1 (low extremity), 2 (moderate extremity), or 3 (high extremity); 1 meaning the respondent indicated they leaned conservative or leaned liberal, 2 meaning the respondent indicated they were conservative or liberal, 3 meaning the respondent indicated they were very conservative or very liberal.
} 
biology were more likely to attribute political ideology to biology than respondents in the control and choice conditions.

\section{Results}

In Experiment 1, we examined the impact of attributing political ideology to biology on prejudice toward political outgroups (H1). More specifically, we modeled the effects of attribution type $(0=$ biology, $1=$ choice $)$ and target ideology $(0=$ ingroup, $1=$ outgroup $)$ on outgroup prejudice (measured as attitudes toward participants' ideological outgroup) ${ }^{4}$. We then ran two linear regression models - one with just the main effects of attribution type and target ideology, and a second with the interaction term (attribution type * target ideology) added (see Table 1). In both models we control for ideological extremity, given that we expected extremity to have a direct and significant effect on attitudes about outgroups, such as prejudice. We found support for this in our first model.

The first model showed no main effect of attribution type (biology vs. choice; $b=-.099$, $S E=.241, p=0.68$ ) or target ideology (ingroup vs. outgroup; $b=.257, S E=.248, p=0.3$ ) on prejudice. These results are reported in Table 1. Ideological extremity independently predicted prejudice, with those who were moderately extreme expressing more prejudice towards ideological outgroups than respondents who were low in ideological extremity $(b=-0.776, S E=$ $0.266, p=0.004)$ and those who were highly extreme expressing more prejudice towards ideological groups than respondents who were low in ideological extremity $(b=-1.545, S E=$ $0.34, p<0.001)$

\footnotetext{
4 The control condition was omitted in the analyses given that the control and choice conditions produced almost identical scores on the manipulation check item, suggesting that the choice condition was similar to participants' baseline attitudes.
} 
The second model revealed a significant interaction of attribution type (biology vs. choice) with target ideology (ingroup vs. outgroup). These results are reported in Table 1. Participants showed similar outgroup attitudes in the choice conditions, regardless of whether they read about an ingroup $(M=2.61, S D=1.42)$ or an outgroup member $(M=2.66, S D=1.28$; $t(50)=0.146, p=0.88)$. However, participants expressed less prejudice in the outgroup biology condition $(M=3.06, S D=1.63)$ compared to the ingroup biology condition $(M=2.275, S D=$ $1.38 ; t(57)=-2.02, p=0.047)$. Participants in the outgroup biology condition also expressed less prejudice than individuals in the choice conditions, although these differences were not statistically significant $(t(56)=1.09, p=0.27$ for outgroup choice condition; $t(52)=-0.89, p=$ 0.37 for ingroup choice condition). Participants in the ingroup choice and ingroup biology conditions expressed similar levels of prejudice $(t(52)=-0.896, p=0.37)$. In sum, while not all contrasts were statistically significant, the overall pattern of results in Experiment 1 was consistent with $\mathrm{H} 1$ - biological attributions about an outgroup member decreased prejudice relative to making choice attributions or biological attributions for an ingroup member.

[Table 1]

[Figure 1]

\section{Experiment 2}

Experiment 2 was designed to test the second hypothesis, that attributing political ideology to biology would lead to reduced intolerance of ideological outgroups, and the third hypothesis, that attributing political ideology to biology would lead to changes in perceptions of polarization. We also increased the sample size for Experiment 2, given that we may not have had sufficient power to test all contrasts in Experiment 1. 


\section{Research Design}

In this experiment, respondents were randomly assigned to read one vignette (from the same list of vignettes used in Experiment 1). After reading the vignette, respondents completed the polarization measure, indicating where they viewed Democrats and Republicans on an ideological spectrum, with -50 being very liberal and 50 being very conservative. Respondents also completed a 9-item tolerance measure (adapted from Haas and Cunningham 2014) to capture general tolerance toward their ideological outgroup ${ }^{5}$. These measures can be found in the Appendix. The order of the dependent variable measures (polarization, tolerance) was counterbalanced. Respondents were a sample from Amazon's Mechanical Turk $(N=377) .10$ respondents were dropped for being unable to identify that Republicans are more conservative than Democrats, leaving a total of 367 cases for analysis. Participation was restricted to residents of the United States and respondents were compensated \$1 USD for their participation. 58\% of respondents were male, $70 \%$ identified as liberal ( $30 \%$ conservative), and the mean age was $35.62(S D=11.17)$. Liberals $(M=1.778, S D=0.78)$ in this sample were more extreme ideologically than conservatives $(M=1.533, S D=0.737 ; t(172.46)=2.626, p=0.009)$

\section{Manipulation Check}

As in Experiment 1, a manipulation check immediately followed the vignette.

Respondents indicated whether they thought biology or personal choices were more influential in determining political ideology. Participants also indicated on a sliding scale (a percentage from 0-100 that did not have to sum to $100 \%$ between the two) how much influence both biology and personal choice have on political ideology (see Appendix). In the choice condition, approximately $10 \%$ of respondents attributed ideology to biology, compared to approximately

\footnotetext{
${ }^{5}$ Example tolerance item: "When you have the right position on some issue, you should keep those with a different political ideology from being heard."
} 
$37 \%$ of respondents in the biology condition $\left(X^{2}(1, \mathrm{~N}=351)=20.078, \mathrm{p}<0.001\right)$. As in

Experiment 1, we expected people to have relatively little prior information about biopolitics research and a low rate of endorsing biological attributions for political ideology, an assumption confirmed by data from the manipulation check. This difference suggests that the manipulation worked as intended--respondents who were encouraged to think about political ideology as being rooted in biology were more likely to attribute political ideology to biology than respondents in the control and choice conditions.

\section{Results}

In this experiment, we examined the effects of attributing political ideology to biology on intolerance $(\mathrm{H} 2)$ and perceptions of polarization $(\mathrm{H} 3)$. The tolerance measure was a composite variable of nine items (Cronbach's $\alpha=0.812$ ) measuring outgroup tolerance (full scale in the Appendix). The mean intolerance score was $3.525(S D=1.089)$ on a scale from $1-6$, with higher values indicating greater intolerance. The mean perception of polarization score was $93.92(S D=$ 24.38 ) with a minimum of 5 and a maximum of 155 , with higher values indicating greater perceptions of polarization. Intolerance and perceptions of polarization were not related $(r(313)$ $=-0.04, p=0.43)$. Similar to Experiment 1, our statistical models focused on two independent variables of interest: $(1)$ attribution type $(0=$ biology, $1=$ choice $)$ and (2) target ideology $(0=$ ingroup, $1=$ outgroup $)^{6}$.

To examine the impact of attributions on intolerance, we then ran two linear regression models - one with just the main effects of attribution type and target ideology, and a second with the interaction term (attribution type * target ideology) added (see Table 2). In both models, we

\footnotetext{
6 The control condition was omitted in the analyses given that the control and choice conditions produced almost identical scores on the manipulation check item $\left(X^{2}(1, \mathrm{~N}=351)=0.551, \mathrm{p}<0.458\right)$, suggesting that the choice condition was similar to participants' baseline attitudes.
} 
control for ideological extremity, coded the same as in experiment 1 . Higher levels on the extremity variable indicated higher levels of ideological extremity (i.e., very liberal or very conservative). As in Experiment 1, we controlled for ideological extremity because we expected extremity to have a direct and significant effect on attitudes about outgroups, such as intolerance. We found support for this in our first model.

The first model showed main effects of both attribution type $(b=0.308, S E=0.145, t=$ $2.118, p=0.035)$ and target ideology $(b=-0.299, S E=0.145, t=-2.06, p=0.04)$. As expected, biological attributions $(M=3.38, S D=1.07)$ led to decreased intolerance compared to choice attributions $(M=3.69, S D=1.02 ; b=0.31, S E=0.14, t=2.118, p=0.035)$. However, generally reading about the foundation of ideology for your ideological outgroup $(M=3.39, S D=1.04)$, when compared to your ideological ingroup $(M=3.71, S D=1.09)$, led to decreased intolerance $(b=-0.299, S E=0.145, t=-2.06, p=0.04)$. Additionally, compared to those participants who expressed low levels of political extremity, respondents who indicated moderate political extremity $(b=0.43, S E=0.16, t=2.667, p=0.008)$ and high political extremity $(b=0.83, S E=$ $0.204, t=4.07, p<0.001)$ expressed greater intolerance for their ideological outgroup. The second model showed no significant interaction effect between attribution type and target ideology $(b=-0.18, S E=0.29, t=-0.63, p=0.52)$, suggesting that in this experiment, making biological attributions for ideology decreased intolerance regardless of whether participants read about an ingroup or an outgroup member. The results of these models are reported in full in Table 2. In sum, biological attributions led to a decrease in tolerance of the ideological outgroup, regardless whose ideology was in question in the vignette.

[Table 2]

[Figure 3] 
Hypothesis 3 suggested that attributing political ideology to biology would lead to a change in perceptions of political polarization, although we were agnostic as to the direction of this change. We used a series of linear regression models to estimate the effects of attribution type, target ideology, and the interaction on perceptions of polarization while controlling for ideological extremity. The polarization score was calculated by subtracting the numerical placement of Democrats from the numerical placement of Republicans, resulting in a numerical representation of distance between the two parties $(M=93.92, S D=24.38)$. We found no main effect of attribution type (biology: $M=92.36, S D=23.74$; choice: $M=93.24, S D=24.41 ; b=$ $0.8675, S E=3.21, t=0.27, p=0.787$ ) or target ideology (ingroup: $M=91.73, S D=25.07$; outgroup: $M=94.17, S E=21.89 ; b=2.439, S E=3.3, t=0.739, p=0.461)$ on perceptions of polarization. Additionally, the attribution type and target ideology interaction was not significant $(b=10.408, S E=6.51, t=1.599, p=0.11)$. These results are reported in full in Table 3.

Given that we found no effect of treatment group on polarization, we conducted an exploratory analysis to look at differences in perceptions of polarization between participants who indicated political ideology is mainly rooted in biology and participants who indicated political ideology is mainly rooted in personal choice (i.e., whether participants selected biology vs. choice to explain ideology after reading the manipulation vignette) on perceptions of polarization. This attribution manipulation check (biology versus choice) variable was substituted for attribution manipulation group (biology versus choice) in the model. We did this exploratory analysis in order to examine the individuals for whom the treatment was effective. Respondents who indicated that biology $(M=85.23, S D=29.94)$ had more influence than personal choices $(M=95.79, S D=22.61)$ on someone's political ideology perceived less polarization $(b=10.175, S E=3.848, t=2.644, p=0.008$; see Table 4$)$. The main effect of target 
ideology was not significant $(b=2.69, S E=3.19, t=0.84, p=0.4)$, and the interaction between attribution type and target ideology was not significant $(b=10.776, S E=7.56, t=1.425, p=$ $0.15)$. While we were agnostic as to the direction of this relationship, the perception of decreased polarization in response to biological attributions would appear to be theoretically consistent with the other findings here - that biological attributions decrease prejudice (Experiment 1) and intolerance (Experiment 2).

[Table 3]

[Table 4]

[Figure 4]

\section{Discussion}

Taken together, the results of these two experiments suggest that political attitudes can shift when individuals learn that political ideology has biological foundations. As the results of our manipulation check suggest, the baseline for biological explanations for political ideology is fairly low, but once individuals are presented with information about the influence of biology on political ideology they adjust their attributions. The average person assigns little responsibility for ideology to biology; in manipulation checks in our studies, only about $7 \%$ of people in the control condition said biology was more influential than personal choices in shaping political ideology (Experiment 1). When asked to determine the proportion of influence on political ideology, respondents said biology had an average of $26.13 \%$ influence compared to an average of $79.5 \%$ influence due to personal choices (Experiment 2). It is possible that the results from biopolitics research on political ideology will not only contribute to political science literature but also have direct implications for and impact on political attitudes in the electorate. 
Specifically, biological attributions for outgroup political ideology led to decreased prejudice toward ideological outgroups and biological attributions led to decreased intolerance toward ideological outgroups. We suspect the attribution and group manipulation is necessary for movement on levels of attitudes because prejudice is more engrained than tolerance; it may be easier to be convinced to afford liberties to your political opposition even if you dislike them. Perhaps being faced with evidence that political ideology is partially predetermined, people are more likely to think of political ideology as a trait that people have less control over, thereby placing less blame on people who are different from them for those differences. This is similar to the narrative surrounding sexual orientation, or the idea that homosexuals should not be punished for a trait they have no control over. For example, if a liberal is born with biological predispositions that lead her to express liberal attitudes, a conservative may be more accepting and even lenient in allowing the liberal to espouse their beliefs, without judgment as to why this liberal may have personally chosen to be a liberal.

Responses we received from a separate survey ${ }^{7}$ asking individuals what their thoughts were about political ideology once they were told ideology has biological foundations support the theoretical justification for this paper. For example, in response to a question asking for thoughts on people who have a different political ideology after learning political ideology is influenced by biology/genetics, one respondent said "Those with a different ideology than mine could not help their different ideas because it is embedded in their genetics and one cannot really change genetics.” Another respondent said “...one cannot change the other person's mind about politics easily because it is a part of how they were born." These thoughts, which were the norm within the answer to this question, support the idea that when people learn about biological

\footnotetext{
${ }^{7}$ This survey was in a pilot study not described in detail in this paper.
} 
foundations of political ideology their attitude about political ideology changes--if biology and genetics help to determine political ideology, people are perceived to have less control or influence over their ideological viewpoints, as opposed to a personal choice that is completely controlled by an individual. Negative feelings about a political outgroup will improve because individuals in that outgroup are not making a deliberative choice to be on the 'other side'. While this is the case in responses about general thoughts about political ideology, context may be important. We may expect these answers to change in an instance where respondents feel threatened by a political outgroup. In that case, biological essentialism of political ideology may fall more in line with research on race and biological essentialism, which suggests a relationship between biological essentialism and prejudicial attitudes.

With implications for tolerance, a respondent said in the free response questions, "If political ideology was influenced by genetics, I would assume that they had no choice in their standing therefore no one should be blamed for what they believe in because they have no control over it." Another respondent said “... even when they have a different political ideology than me, even when it's the 'wrong' one, it's not their fault." Similar responses were prevalent and suggest that once people learn that political ideology has biological foundations they are more sympathetic towards other ideologies, or at least hold differences in ideology against a person less, as many respondents also mentioned how people should not be judged for having an ideology that they were biologically predisposed to hold. This sort of thinking helps explain the mechanism behind the tolerance results in this paper. As one of the last respondents said, "If this [ideology is influenced by biology/genetics] is true I would be more tolerant of people with a different ideology because it's due to their genetic makeup." 
As evidenced by effects of biological attributions on attitudes and tolerance, people feel better about ideological outgroups when they think about ideology as being rooted in biology. Feeling more positively about a group makes it less likely that one will want to distance themselves from that group. A person has less of an incentive to differentiate themselves from another person on a certain trait if that trait is viewed in a more positive way. It may be that the main mechanism hypothesized, the need to create two distinct ideological groups that do not share any space on a continuum, is only necessary under negative circumstances. If the ideological outgroup poses some sort of challenge or direct threat, it is possible that essentializing will lead people to distance themselves from the outgroup, making essentialization a process that polarizes Democrats and Republicans in one's mind.

\section{Conclusion}

Political attitudes vary as a function of attributions for political ideology, or what people see as the foundation of political ideology (i.e., whether ideology is rooted in biology or a personal choice people make). Taken together, the results of these experiments suggest that attributing political ideology to biology does influence attitudes broadly and has consequences for both political intolerance and polarization. Those who are encouraged to consider the political ideology of their political opposition as being rooted in biology have less prejudice toward their ideological outgroup. Additionally, attributing political ideology to biology leads to a decrease in intolerance of ideological outgroups and a decrease in the perception of political polarization. As a whole, these results suggest that people feel more warmly towards their ideological outgroup after being presented with evidence that biology at least partially influences one's political ideology. 
Future work should examine the mechanism behind biological attributions being associated with the perception of less polarization, even though previous work suggests that essentializing political ideology should lead to more distinct and separated groups. One possibility is that if outgroups pose a threat, this would override any sort of positive attitude movement brought on by biological attributions. The presence of threat or the potential of competition (say, an upcoming election) will likely cause people to distance themselves from outgroups.

Perhaps polarization is such an engrained part of political evaluation and cognition that a person's preconceived notions about polarization will not change as a result of a few sentences about the roots of ideology. A worthwhile next step could be repeated exposure to information about political ideology's roots in biology since this paper cannot speak to the impact of receiving similar information across a longer span of time or, alternatively, if the effects found in this paper are long-lasting or dissipate. Since respondents in these studies expressed their attitudes immediately after treatment, we have no way of knowing what the long-term effects may be. It is also possible that people who attribute political ideology to biology are just more likely to see less distance between parties for other reasons and un unknown common variable affects both. Future work may wish to examine other mechanisms that lead to both attribution type and perception of polarization. 


\section{References}

Alford, J. R., Funk, C. L., \& Hibbing, J. R. 2005. “Are Political Orientations Genetically Transmitted?" American Political Science Review, 99(2), 153-167.

Coleman, J. and Hong, Y. 2008. "Beyond Nature and Nurture: The influence of Lay Gender Theories on Self-Stereotyping." Self and Identity, 7, 34-53.

Fowler, J. H., Baker, L. A., \& Dawes, C. T. 2008. "Genetic Variation in Political Participation." American Political Science Review, 102(2), 233-248.

Garretson, J., \& Suhay, E. 2016. "Scientific Communication about Biological Influences on Homosexuality and the Politics of Gay Rights." Political Research Quarterly, 69(1), 17-29.

Gelman, S. A. 2003. “The Essential Child: Origins of Essentialism in Everyday Life.” New York, NY: Oxford University Press.

Haider-Markel, D. P., and Joslyn, M. R. 2008. "Beliefs about the Origins of Homosexuality and Support for Gay Rights: An Empirical Test of Attribution Theory.” Public Opinion Quarterly, 72(2), 291-310.

Haas, I. J. and Cunningham, W. A. 2014. “The Uncertainty Paradox: Perceived Threat Moderates the Effect of Uncertainty on Political Tolerance. Political Psychology, 35(2): 291-302.

Haslam, N. Rothschild, L., and Ernst, D. 2000. "Essentialist Beliefs about Social Categories.” The British Journal of Social Psychology, 39, 113-127.

Hatemi, P. K., and McDermott, R. (Eds.). 2011.” Man is by Nature a Political Animal: Evolution, Biology, and Politics.” University of Chicago Press.

Hegarty, P. 2002. “It's Not a Choice, it's the Way We're Built: Symbolic Beliefs about Sexual Orientation in the US and Britain." Journal of Community and Applied Social 
Psychology, 12(3), 153-166.

Hibbing, J. R., Smith, K. B., and Alford, J. R. 2013. "Predisposed: Liberals, Conservatives, and the Biology of Political Differences." Routledge.

Hunt, M. O. 1996. "The Individual, Society, or Both? A Comparison of Black, Latino, and White Beliefs about the Causes of Poverty." Social Forces (75)1: 293-322.

Keller, J. 2005. "In Genes We Trust: The Biological Component of Psychological Essentialism and its Relationship to Mechanisms of Motivated Social Cognition." Journal of Personality and Social Psychology, 88(4), 686.

Klugel, J. 1990. “Trends in Whites' Explanations of the Black-White Gap in Socioeconomic Status, 1977-1989." American Sociological Review, 512-525.

Morris, J. P., Squires, N. K., Taber, C. S., and Lodge, M. 2003. “Activation of Political Attitudes: A Psychophysiological Examination of the Hot Cognition Hypothesis.” Political Psychology, 24(4): 727-745.

Nicholson, S. P., Carman, C. J., Coe, C. M., Feeney, A., Fehér, B., Hayes, B. K., Kam, C., Karp, J. A., Vaczi, G., \& Heit, E. 2018. “The Nature and Party Categories in Two-Party and Multiparty Systems." Political Psychology, 39(1), 279-304.

Roberts, S. O., Ho, A. K., Rhodes, M., and Gelman, S. A. 2017. "Making Boundaries Great Again: Essentialism and Support for Boundary-Enhancing Initiatives." Personality and Social Psychology Bulletin, 43(12), 1643-1658.

Rothbart, M. and Taylor, M. 1992. "Category Labels and Social Reality: Do We View Social Categories as Natural Kinds? In G. R. Semin and K. Fiedler (Eds.), Language, Interaction, and Social Cognition (pp. 11-36). Thousand Oaks, CA: SAGE. 
Schneider, S. P., Smith, K. B., \& Hibbing, J. R. 2018. Genetic Attributions: Sign of Intolerance or Acceptance?" The Journal of Politics, 80(3), 1023-1027.

Suhay, E., Brandt, M. J., \& Proulx, T. 2017. "Lay Belief in Biopolitics and Political Prejudice." Social Psychological and Personality Science, 8(2), 173-182.

Tajfel, H. 1970. Experiments in Intergroup Discrimination." Scientific American, 223(5), 96-103.

Tajfel, H. Billig, M. G., Bundy, R. P., \& Flament, C. 1971. "Social Categorization and Intergroup Behaviour." European Journal of Social Psychology, 1(2), 149-178.

Williams, M. L., and Eberhardt, J. L. 2008. "Biological Conceptions of Race and the Motivation to Cross Racial Boundaries." Journal of Personality and Social Psychology, 94, 10331047. 
Figure 1: Effects of Attribution on Prejudice

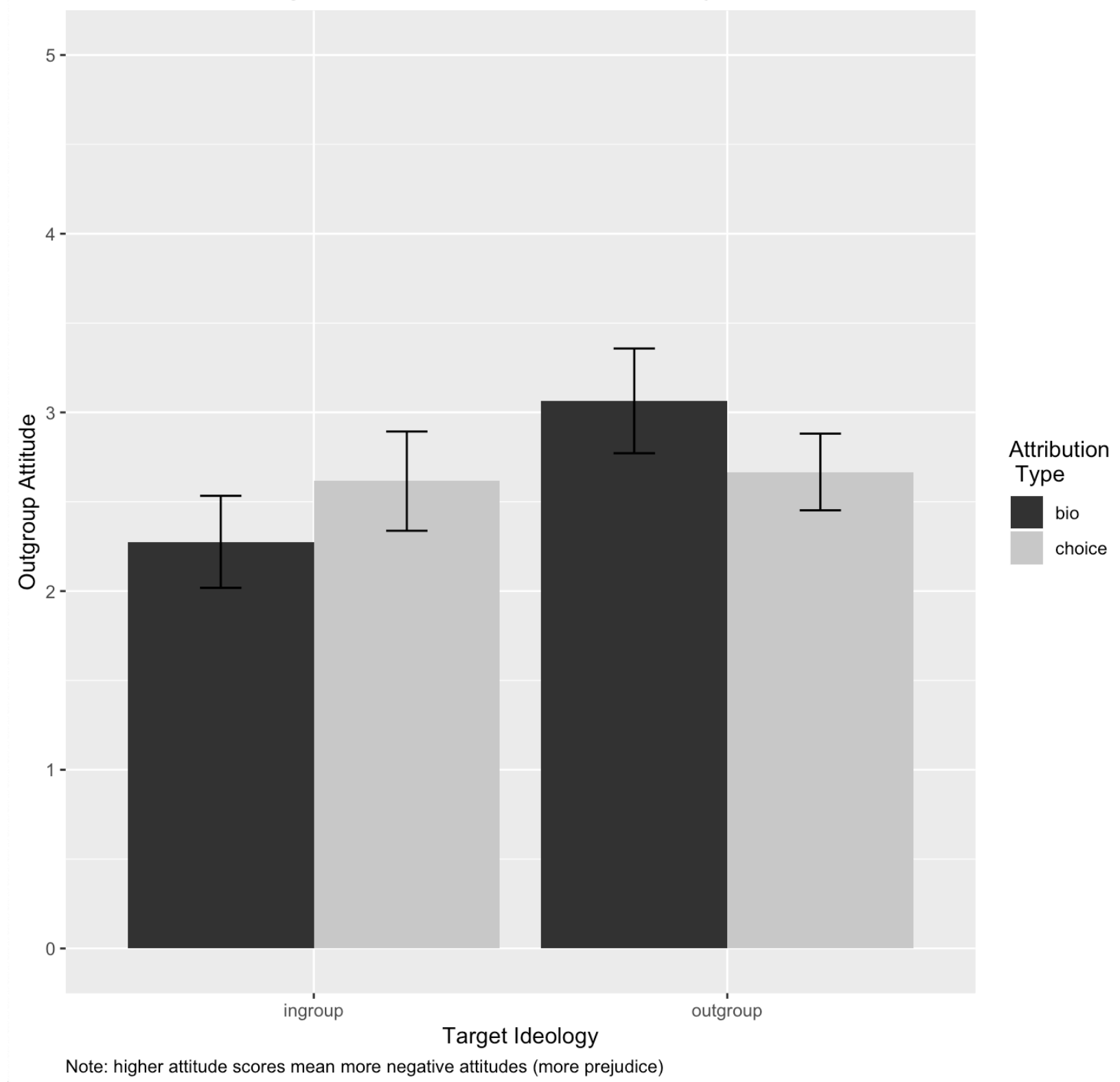


Figure 2: Effects of Attribution on Intolerance

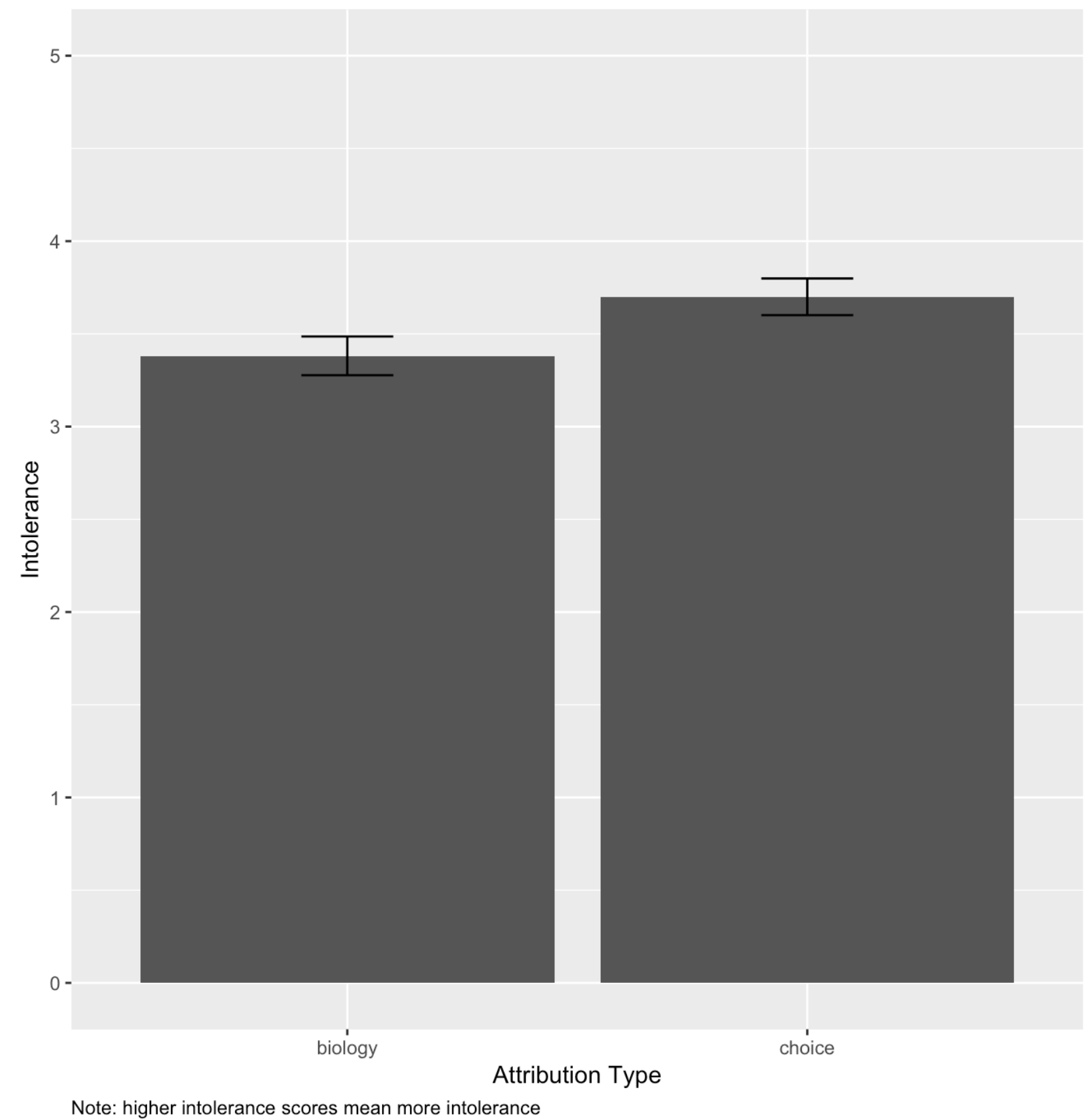


Figure 3: Effects of Attribution on Perception of Polarization

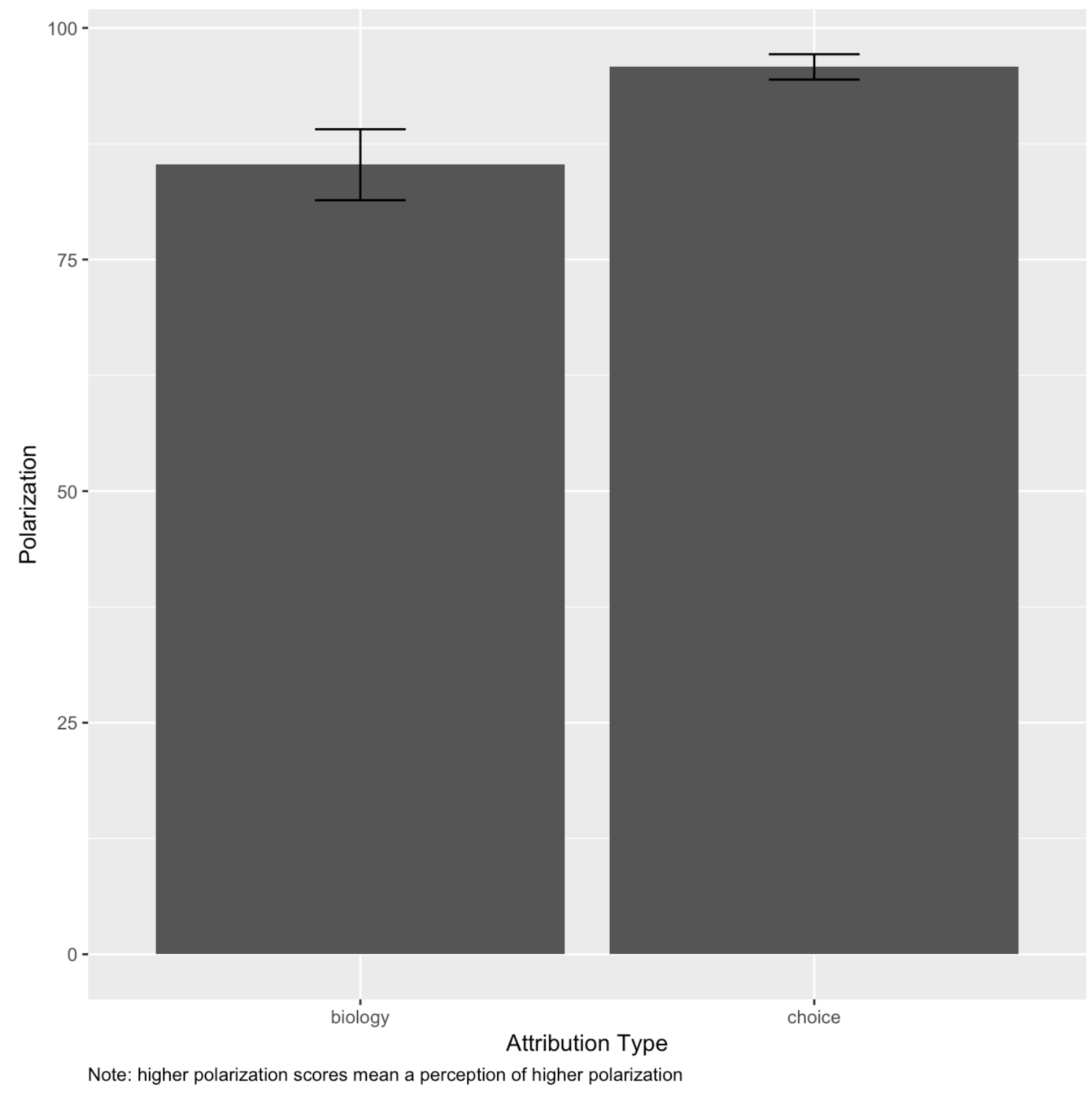


Table 1: Effects of Attribution Type and Target Group on Prejudice

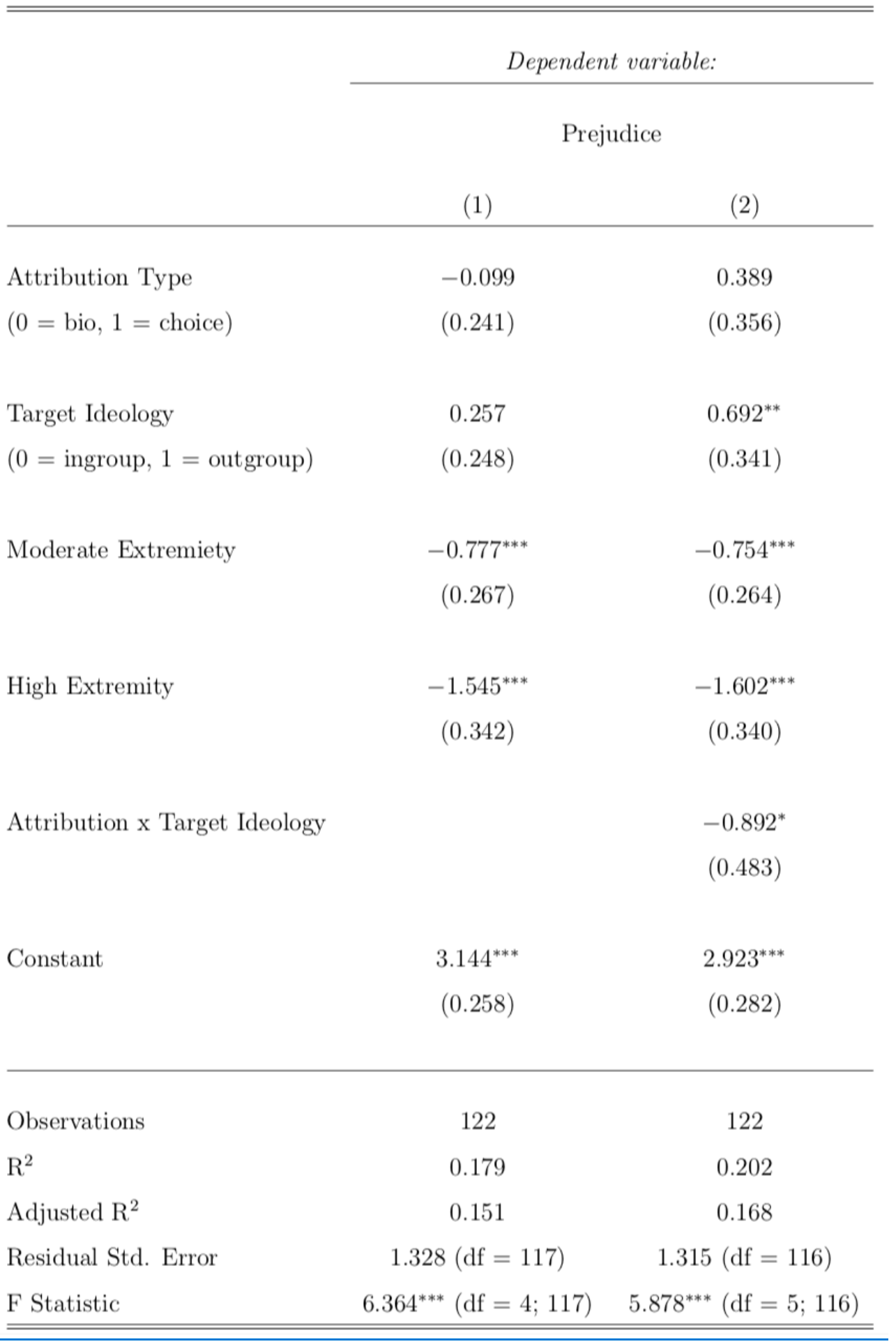


Table 2: Effects of Attribution Type and Target Group on Tolerance

Dependent variable:

Tolerance

(1)

(2)

Attribution Type
$(0=$ bio, $1=$ choice $)$

$0.308^{* *}$

$0.399^{*}$

(0.145)

$(0.205)$

Target Ideology

$-0.299^{* *}$

$-0.204$

$(0=$ ingroup, $1=$ outgroup $)$

(0.145)

(0.209)

Moderate Extremity

$0.430^{* * *}$

$0.434^{* * *}$

$(0.161)$

(0.162)

High Extremity

$0.831^{* * *}$

$0.814^{* * *}$

(0.204)

(0.206)

Attribution Type $\mathrm{x}$ Target Ideology

$-0.185$

(0.294)

Constant

$3.243^{* * *}$

$3.200^{* * *}$

(0.145)

(0.161)

Observations

196

196

$\mathrm{R}^{2}$

0.132

0.134

Adjusted $\mathrm{R}^{2}$

0.114

0.111

Residual Std. Error

$1.014(\mathrm{df}=191)$

$1.016(\mathrm{df}=190)$

F Statistic

$7.277^{* * *}(\mathrm{df}=4 ; 191) \quad 5.883^{* * *}(\mathrm{df}=5 ; 190)$ 
Table 3: Effects of Attribution Type and Target Ideology on Polarization

\begin{tabular}{|c|c|c|}
\hline & \multicolumn{2}{|c|}{ Dependent variable: } \\
\hline & \multicolumn{2}{|c|}{ Polarization } \\
\hline & (1) & $(2)$ \\
\hline Attribution Type & -0.182 & -5.290 \\
\hline$(0=$ bio, $1=$ choice $)$ & $(3.212)$ & $(1.542)$ \\
\hline Target Ideology & 3.091 & -2.278 \\
\hline$(0=$ ingroup, $1=$ outgroup $)$ & $(3.245)$ & $(4.661)$ \\
\hline \multirow[t]{2}{*}{ Moderate Extremity } & $8.312^{* *}$ & $8.094^{* *}$ \\
\hline & $(3.586)$ & $(3.575)$ \\
\hline \multirow[t]{2}{*}{ High Extremity } & $14.434^{* * *}$ & $15.219^{* * *}$ \\
\hline & $(4.610)$ & $(4.618)$ \\
\hline \multirow[t]{2}{*}{ Attribution Type x Target Ideology } & & 10.408 \\
\hline & & $(6.509)$ \\
\hline \multirow[t]{2}{*}{ Constant } & $86.125^{* * *}$ & $88.578^{* * *}$ \\
\hline & $(3.270)$ & $(3.601)$ \\
\hline Observations & 204 & 204 \\
\hline $\mathrm{R}^{2}$ & 0.058 & 0.070 \\
\hline Adjusted $\mathrm{R}^{2}$ & 0.039 & 0.046 \\
\hline Residual Std. Error & $23.086(\mathrm{df}=199)$ & $22.996(\mathrm{df}=198)$ \\
\hline F Statistic & $3.048^{* *}(\mathrm{df}=4 ; 199)$ & $2.968^{* *}(\mathrm{df}=5 ; 198)$ \\
\hline
\end{tabular}


Table 4: Effects of Attribution Belief and Target Ideology on Polarization

\begin{tabular}{|c|c|c|}
\hline & \multicolumn{2}{|c|}{ Dependent variable: } \\
\hline & \multicolumn{2}{|c|}{ Polarization } \\
\hline & (1) & $(2)$ \\
\hline Attribution Belief & $10.336^{* * *}$ & 5.441 \\
\hline$(0=$ bio, $1=$ choice $)$ & $(3.755)$ & $(5.083)$ \\
\hline Target Ideology & 2.695 & -5.547 \\
\hline$(0=$ ingroup, $1=$ outgroup $)$ & $(3.197)$ & $(6.607)$ \\
\hline \multirow[t]{2}{*}{ Moderate Extremity } & $8.303^{* *}$ & $8.409^{* *}$ \\
\hline & $(3.536)$ & $(3.528)$ \\
\hline \multirow[t]{2}{*}{ High Extremity } & $14.488^{* * *}$ & $15.172^{* * *}$ \\
\hline & $(4.525)$ & $(4.539)$ \\
\hline \multirow[t]{2}{*}{ Attribution Belief x Target Ideology } & & 10.776 \\
\hline & & $(7.564)$ \\
\hline \multirow[t]{2}{*}{ Constant } & $78.251^{* * *}$ & $81.703^{* * *}$ \\
\hline & $(3.997)$ & $(4.666)$ \\
\hline Observations & 203 & 203 \\
\hline $\mathrm{R}^{2}$ & 0.092 & 0.101 \\
\hline Adjusted $\mathrm{R}^{2}$ & 0.074 & 0.079 \\
\hline Residual Std. Error & $22.687(\mathrm{df}=198)$ & $22.628(\mathrm{df}=197)$ \\
\hline F Statistic & $5.028^{* * *}(\mathrm{df}=4 ; 198)$ & $4.449^{* * *}(\mathrm{df}=5 ; 197)$ \\
\hline
\end{tabular}




\section{Appendix}

Treatment vignettes

Respondents were assigned to receive one of the six vignettes.

1. Choice (liberal): Jordan's parents and grandparents both hold politically conservative ideals and align with politically conservative politicians. Jordan, who recently graduated college, identified as a political conservative in high school but now identifies as a political liberal because liberal ideas make the most sense now. This makes sense since studies have shown political ideology changes (Roberts, Walton, and Viechtbauer, 2006).

2. Choice (conservative): Jordan's parents and grandparents both hold politically liberal ideals and align with politically liberal politicians. Jordan, who recently graduated college, identified as a political liberal in high school but now identifies as a political conservative because conservative ideas make the most sense now. This makes sense since studies have shown political ideology changes (Roberts, Walton, and Viechtbauer, 2006).

3. Biology (conservative): Jordan's parents and grandparents both hold politically conservative ideals and align with politically conservative politicians. Jordan, who recently graduated college, has identified as a political conservative since high school because conservative ideals have just come naturally. This makes sense since studies have shown there is a genetic component to ideology (Bell, Schermer, and Vernon, 2009).

4. Biology (liberal): Jordan's parents and grandparents both hold politically liberal ideals and align with politically liberal politicians. Jordan, who recently graduated college, has identified as a political liberal since high school because liberal ideals have just come naturally. This makes sense since studies have shown there is a genetic component to political ideology (Bell, Schermer, and Vernon, 2009).

5. Control (liberal): Jordan, who recently graduated college, identifies as a political liberal. Recently, Jordan went out for pizza with extended family and received some book recommendations while they were eating.

6. Control (conservative): Jordan, who recently graduated college, identifies as a political conservative. Recently, Jordan went out for pizza with extended family and received some book recommendations while they were eating. 


\section{Polarization measure}

The absolute value of placement of Democrats on the ideological scale (from -50, extremely liberal, to 50, extremely conservative) was added to the value of placement of Republicans to create a numerical distance between parties. Larger number indicated more distance. This measure is used as a measure of perception of polarization.

Please use the sliding markers below to place the Democrats and Republicans along the spectrum of very liberal (-50) to very conservative (50).

For example, placing the marker at 0 would mean the group is moderate.

\begin{tabular}{|l|l|l|l|l|l|l|l|l|l|l|l|l|l|}
\hline Democrats & -50 & -30 & -20 & -10 & 0 & 10 & 20 & 30 & 40 & 50 \\
\hline & & & & & & & & & & \\
\hline & & & & & & & & & & & \\
\hline Republicans & & & & & & & & & & & \\
\hline
\end{tabular}


Tolerance items (modified from Haas \& Cunningham 2014)

All items are rated on a 1-6 scale with 1 being strongly disagree and 6 being strongly agree.

1. When you have the right position on some issues, you should keep those with a different political ideology from being heard.

2. Even if an idea from someone with a different political ideology seems wrong, it should have as much change to influence people as an idea that seems right.

3. I don't mind at all when people with a different political ideology have opinions about issues that I know are wrong.

4. We need to actively oppose people with a different political ideology.

5. When people with a different political ideology are obviously wrong in their opinions, they need to be corrected.

6. Ideas from people with my political ideology are just more right than from people with a different political ideology, and our society should do all it can to see that the right ideas win out over the wrong ideas.

7. The media should not pay much, if any, attention to people who clearly hold the wrong opinions from a political ideology different than mine.

8. Children should be taught from an early age to think about social issues the way my political ideology does.

9. I get angry when I hear people from a different political ideology stating opinions that I think are wrong. 